\title{
Number of Mild Episodes
}

National Cancer Institute

\section{Source}

National Cancer Institute. Number of Mild Episodes. NCI Thesaurus. Code C124328.

The number of times an event, which is classified as mild, occurred. 